\title{
Educação técnica e integração: a política de criação dos Institutos Federais de Fronteiras ${ }^{1}$
}

\author{
Educación técnica y integración: la política de creación de los \\ Institutos Federales de Fronteras
}

\author{
Technical education and integration: the policy of creation of Federal \\ Institutes of Borders
}

\author{
Me Andréa Marcia Legnani² \\ Dra . Silvana Aparecida de Souza ${ }^{3}$
}

\begin{abstract}
Resumo
Este trabalho apresenta um estudo preliminar sobre as possibilidades e desafios da implantação dos Institutos Federais de Fronteira (IFF's), envolve analisar as categorias território, fronteira, integração, educação profissional, políticas públicas e educacionais, que permeiam o tema abordado. A pesquisa tem a abordagem qualitativa, que utiliza como estratégia metodológica o estudo comparativo, envolve a consulta bibliográfica e documental. Tem como objetivo compreender e analisar como se efetiva a política de implantação de Institutos Federais de Fronteira. Optou-se pelo o estudo comparado, pois possibilitou a análise de dois casos de instituições de ensino distintas, observando-os em suas peculiaridades locais e temporais, além de, proporcionar uma interpretação numa perspectiva em que aborda uma temática no campo da educação profissional em região de fronteira, comparando a implantação do Instituto Federal Sul-rio-grandense (IFSUL) Campus Santana do Livramento que apresenta uma experiência na oferta de cursos binacionais entre instituições de ensino do Brasil e Uruguai e o Instituto Federal do Paraná (IFPR) - Campus Foz do Iguaçu o qual oferta vagas em curso subsequente para alunos oriundos do Paraguai e Argentina.
\end{abstract}

Palavras-Chave: Educação Profissional; Fronteira; Políticas Públicas; Território.

\section{Resumen}

Este trabajo presenta un estudio preliminar sobre las posibilidades y desafíos de la implantación de los Institutos Federales de Frontera (IFF's), involucra analizar las categorías territorio, frontera, integración educación profesional, políticas públicas y educativas, que permean el tema abordado. La investigación tiene el abordaje cualitativo, que utiliza como estrategia metodológica el estudio comparativo, involucra la consulta bibliográfica y documental. Tiene como objetivo comprender y analizar cómo se efectúa la política de implantación de

\footnotetext{
${ }^{1}$ Artigo apresentado no Simpósio Temático Políticas públicas, diversidade cultural e desconolização durante o II Seminário Latino-Americano de Estudos em Cultura - SEMLACult em Foz do Iguaçu/PR, Brasil, 2018.

${ }^{2}$ Mestre em Sociedade, Cultura e Fronteiras; Doutoranda do Programa de Pós-Graduação Stricto Sensu Sociedade, Cultura e Fronteira da Universidade Estadual do Oeste do Paraná; Pedagoga do Instituto Federal do Paraná; Foz do Iguaçu, Paraná, Brasil. E-mail: andrea.legnani@ hotmail.com

3 Pós-doutora no Programa de Pós-graduação em Política Social (PPGSP) da UnB, Doutorado em Educação pela USP, Professora Associada do Programa de Pós-Graduação Stricto Sensu Sociedade, Cultura e Fronteiras da Universidade Estadual do Oeste do Paraná, Foz do Iguaçu, Paraná, Brasil. E-mail: silvana.souza @ unioeste.br
} 
Institutos Federales de Frontera. Se optó por el estudio comparado, pues posibilitó el análisis de dos casos de instituciones de enseñanza distintas, observándolos en sus peculiaridades locales y temporales, además de, proporcionar una interpretación en una perspectiva en que aborda una temática en el campo de la educación profesional en región de frontera, comparando o Instituto Federal Sul-rio-grandense (IFSUL) Campus Santana do Livramento que presenta una experiencia en la oferta de cursos binacionales entre instituciones de enseñanza de Brasil y Uruguay y el Instituto Federal de Paraná (IFPR) - Campus Foz do Iguaçu o Brasil, que ofrece vacantes en curso subsecuente para alumnos oriundos de Paraguay y Argentina.

Palabras claves: Educación Profesional; Frontera; Políticas Públicas; Territorio.

\begin{abstract}
This work presents a preliminary study about the possibilities and challenges of implantation of the Federal Institutes of Border (IFFs). It involves the analyses of the categories: territory, border, professional education, public and educational policies, which involve the approached theme. The research has the qualitative approach, which uses the comparative study as a methodological approach, involving documental and bibliographical search. The aim is to comprehend and analyze how the policy of implantation of the Institutes of Border turns into effect. The option was for a compared study, as it enabled the analysis of two cases from different learning institutions, observing them on their local and temporal peculiarities and also provide an interpretation on a perspective that approaches the themes of a border region professional education, compared to the process of implementation of Sul-rio-grandense Federal Institute (IFSUL) campus Santana do Livramento which presents the offer of binational courses among learning institutions of Brazil and Uruguay and the Federal Institute of Paraná (IFPR) - campus Foz do Iguaçu, which offers the enrollment in subsequent courses for students from Paraguay and Argentina.
\end{abstract}

Key-words: Professional Education, Border, Public and Educational Policies, Territory.

\title{
1. Introdução
}

Procurar conceituar as categorias fronteira, território e integração, bem como as questões ligadas às políticas públicas e educacionais, além de relacioná-las a educação profissional no sentido de analisar as possibilidades e desafios da implantação de Institutos Federais de Fronteira (IFF's), é o objetivo deste estudo.

O trabalho aqui apresentado é um recorte do projeto de pesquisa para doutorado no qual se configura como objeto de estudo a seguinte problematização: quais os limites e possiblidades na implantação de um Instituto Federal de Fronteira? - Para responder tal questionamento apresenta-se como hipótese a ser investigada: ao que parece a definição do perfil desses institutos bem como o processo de escolha dos cursos em tais instituições são decisões tomadas por gestores das instituições pesquisadas, dirigentes políticos, e não pela comunidade local e isso pode talvez não contemplar a necessidade da demanda regional por qualificação profissional.

Tal proposta de pesquisa se justifica na perspectiva em que aborda uma temática no campo da educação profissional em região de fronteira, com um estudo comparado entre um "Instituto de Fronteira" (IFSUL) Campus Santana do Livramento, que conforme Silva e Lima (2015) é uma experiência tida como exitosa e pioneira na oferta de cursos binacionais na 
América Latina e um "Instituto na Fronteira" (IFPR - Campus Foz do Iguaçu) o qual oferta vagas em curso subsequente para alunos oriundos do Paraguai e Argentina.

A pesquisa tem abordagem qualitativa, que conforme Flick (2009, p. 37) "dirige-se à análise de casos concretos em suas peculiaridades locais e temporais, partindo das expressões e atividades das pessoas em seus contextos locais".

Como estratégia metodológica optou-se pelo estudo comparado, envolvendo consulta bibliográfica e documental, pois a pesquisa comparativa “[...] interpreta e constrói fatos não se limitando a descobri-los ou a descrevê-los" (NÓVOA, p. 52, 2009), o que torna o estudo instigante e interessante porque "Eis que põe em causa toda uma série de dicotomias constitutivas das nossas concepções de ciência (sujeito/objeto, texto/contexto, corpo/espirito, etc.) convidando-nos a pensar de outra maneira nosso trabalho" (Id. Ibid).

A estrutura deste artigo está assim disposta: no primeiro item traz a contextualização do objeto de estudo por meio da fundamentação teórica com a abordagem das categorias: território, fronteira e integração procurando fazer uma articulação entre a função do Estado, políticas públicas e educação profissional; no segundo item, descreve a experiência no campo da educação profissional em região de fronteira, IFSUL- Campus Santana do Livramento, e o IFPR - Campus Foz do Iguaçu, abordando algumas indicações do que foi possível analisar e compreender até o momento e, finalizando, apresenta as considerações finais.

\section{A relação entre território, fronteira, integração, educação profissional e políticas públicas}

A ideia aqui é buscar conceituar e estabelecer relações entre as categorias que servem de base para construção de uma fundamentação teórica sobre o tema em estudo, iniciando por território e fronteira, fazendo um aporte no que diz respeito à integração correlacionado tal arcabouço com educação profissional, políticas públicas e o papel do Estado diante de tal contextualização.

Se atendo ao conceito geográfico, o território é formado a partir do espaço, que é resultado de uma ação conduzida por um sujeito; que, ao se apropriar do espaço, concreta ou abstratamente "territorializa" tal espaço (RAFFESTIN, 1993). Sendo assim, a territorialidade retrata a multidimensionalidade do "vivido" territorial pelo coletivo social, por meio de relações que podem ser existenciais e/ou produtivistas. Sendo relações consideradas de poder, pois são estabelecidas na interação entre os sujeitos que procuram transformar, tanto as suas relações com a natureza, como as relações sociais entre si (Id. Ibid). 
Essas relações de poder delimitam o espaço do território interferindo na territorialidade, bem como na dinâmica das relações sociais, culturais, econômicas e de produção, pois como Raffestin (1993, p. 159) destaca, “O poder é inevitável e, de modo algum, inocente", sendo assim pode-se dizer que o poder também delimita fronteiras.

E em se tratando de uma noção conceitual de fronteira, depara-se com uma categoria de sentido polissêmico, amplamente debatido em diferentes áreas do conhecimento. De acordo com a abordagem de Nogueira (2007, p. 29), "as origens políticas do conceito estão associadas à própria formação dos Estados-nacionais, que no seu processo de consolidação tiveram, e ainda tem que demarcar claramente as linhas divisórias [...]". Para Curcio, fronteira é uma construção histórica, que delimita domínios, estando relacionada a disputas de poder, a defesa de territórios e limites legais (CURCIO, 2014).

Por sua vez, Albuquerque destaca que (2009, p. 159) "as fronteiras nacionais políticas são criações humanas, delimitadas e demarcadas sucessivamente de acordo com os processos de ocupação militar, demográfica, econômica, política e cultural que ocorrem nos territórios limítrofes".

No que interessa a este estudo, a representação da ideia de fronteira, vai além das abordagens tradicionais, têm uma perspectiva ampla, buscando trazer uma visão crítica e múltipla, abarcando também as questões culturais, que, por sua vez induzem a pensar a fronteira no sentido de "pensar na passagem, na comunicação, no diálogo e no intercâmbio" (PESAVENTO, 2002, p. 36), configurando assim "um trânsito não apenas de lugar, mas também de situações ou épocas, assim como de população, esta dimensão aponta para uma nova reflexão: a de que, pelo contato e permeabilidade, a fronteira é, sobretudo, híbrida e mestiça" (Id. Ibid).

Assim, a fronteira tem variados sentidos construídos pelas populações locais que vivem o cotidiano das travessias e dos controles estatais. Para estas populações, outras fronteiras constroem-se por meio do comércio na fronteira, das redes de amizades, dos familiares, isso ultrapassa os limites políticos, estando em constante movimento e negociação (ALBUQUERQUE, 2009).

No que tange à legislação em relação à fronteira, a Lei Federal nº 6.634, de 1979 que dispõe sobre a delimitação da área fronteira, estabelece que é considerada área indispensável à Segurança Nacional a faixa interna de $150 \mathrm{Km}$ (cento e cinquenta quilômetros) de largura, paralela à linha divisória terrestre do território nacional, sendo designada como Faixa de Fronteira. 
A responsabilidade sobre a demarcação de limites é do Estado. Sendo assim o Estado elabora políticas para ordenar do território em termos de limites físicos e sociais permeado pelas relações capitalistas de produção. Neste caso, o Estado é o detentor do poder de legislar sobre a ordem e a regulação do uso social do território, sendo então, o maior ordenador e controlador de tais normativas (LUCHETTI, 2014).

Se atendo um pouco mais e para fazer uma reflexão mais detalhada e crítica em relação ao papel do Estado na organização do território, recorre-se a Friedrich Engels e sua obra "A origem da família, da propriedade privada e do Estado". Nessa obra o autor traz um estudo sobre as três formas pelas quais se originou o Estado em Atenas, Roma e pelos germanos. Destacando que o Estado,

É antes um produto da sociedade, quando esta chega a um determinado grau de desenvolvimento; é a confissão de que esta sociedade se enredou numa irremediável contradição com ela própria e está dividida por antagonismos irreconciliáveis que não consegue conjurar. Mas para que esses antagonismos, essas classes com interesses econômicos colidentes não se devorem e não consumam a sociedade numa luta estéril, faz-se necessário um poder colocado aparentemente por cima da sociedade, chamado a amortecer o choque e a mantê-lo dentro dos limites da “ordem”. Este poder, nascido da sociedade, mas posto acima dela se distanciando cada vez mais, é o Estado (ENGELS, 1984, p. 191).

Engels ainda argumenta que o Estado se originou por necessidade de conter o antagonismo das classes em meio ao conflito entre as mesmas, sendo o Estado da classe econômica e politicamente dominante adquirindo assim novas formas de exploração dos oprimidos.

Em relação ao antagonismo entre as classes, para Marx e Engels (2005, p. 40), “a história de todas as sociedades que existiram até nossos dias tem sido a história da luta de classes”. Tal afirmação elaborada em 1848, no Manifesto Comunista, e que continua vigente se observarmos o desenvolvimento das sociedades sob uma perspectiva crítica na qual sempre houve no decorrer da história uma classe dominante que explora para manter seus privilégios e uma classe de explorados que vende sua força de trabalho para tentar sobreviver.

Trazendo para atualidade pode-se dizer que apesar de com o tempo e o desenvolvimento das sociedades o papel do Estado também tenha evoluído em alguns aspectos, ainda pode-se observar a preponderância das classes dominantes na organização e 
dinâmica do Estado, o que envolve além dos aspectos econômicos e políticos questão da implantação de políticas públicas para área social e educacional.

A elaboração e a implantação de políticas públicas são necessárias como forma de ordenação do território, pois há necessidade de planejamento para o desenvolvimento das localidades e da convivência social. Mas, por vezes, as políticas públicas implantadas na região fronteira encontram dificuldades para ser efetivada como barreiras legais e diplomáticas, falta de articulação com o centro político decisório do país, a falta de informações sobre a região e a informalidade de diversas ações executadas para implantação das mesmas (LUCHETTI, 2014).

$\mathrm{Na}$ implantação de políticas públicas em região de fronteira alguns aspectos precisam ser levados em consideração, além do contexto político, econômico e administrativo a diversidade cultural que permeia tal região deve ser observada, bem como os fluxos transfronteiriços que acontecem todos os dias entre os países vizinhos.

As políticas federais relacionadas à faixa de fronteira englobam vários órgãos governamentais, cada um com normativas próprias e atribuições em diversas linhas de ação, as quais precisam ser realizadas conjuntamente, por meio de uma infraestrutura adequada e controles apropriados para que suas atuações sejam produtivas de modo a possibilitar que os objetivos comuns sejam alcançados (TCU, 2014).

Os fluxos transfronteiriços no contexto educacional variam muito de acordo com o nível de desenvolvimento das cidades. Algumas dificuldades como: a diferenças de idioma, cultura, altos custos e questões burocráticas que envolvem o reconhecimento de diplomas inibem a movimentação de estudantes e profissionais estrangeiros para as cidades vizinhas, principalmente no que diz respeito ao ensino superior (BRASIL, 2005).

Tal situação apresenta-se como um desafio na área educacional, corroborando com a ideia de que, "Cooperação e integração entre países configuram-se num desafio constante, complexo e repleto de dificuldades, e que traz a questão da implantação destes Institutos de Fronteira para o centro das discussões (LEGNANI e CURY, 2018, p. 250)”.

Mas, a fronteira considerada um marco divisório, de separação entre países, territórios, estados, cidades pode ser vista sob a perspectiva da integração. Usualmente, "integração" é conceituada como a junção de várias partes num todo. Na literatura da ciência econômica, não há um significado claro a respeito do conceito de "integração econômica". Há autores que incluem a integração social neste conceito, outros a consideram como várias formas de cooperação internacional, defendendo que a simples existência de relações comerciais entre economias independentes já é uma demonstração de integração (BALASSA, 1982). 
No contexto deste estudo a concepção de integração parte de uma perspectiva de cooperação e solidariedade, envolvendo as dimensões política, social, educacional e cultural em prol do desenvolvimento, da soberania e do bem estar das populações fronteiriças.

Em relação à educação como agente de integração, e mais especificamente a educação profissional cabe fazer aqui um aparte para refletir sobre a forma como a mesma vem sendo implementada no Brasil. Para Frigotto (2005), as políticas de formação profissional no Brasil, são políticas de formação emergenciais ou centradas na ideia de treinamento.

Neste sentido pode-se trazer para discussão o pensamento de Karl Marx, destacado em sua obra "O Capital: critica da economia politica":

A fim de modificar a natureza humana, de modo que alcance habilidade e destreza em determinada espécie de trabalho e se torne força de trabalho desenvolvida e especifica, é mister educação ou treino que custa uma soma maior ou menor de valores de mercadorias (MARX, p. 202, 2017).

É perceptível assim, que na visão capitalista da educação profissional esta se reduz ao treinamento de habilidades, meramente para atender as demandas da produção, não se preocupando com a formação integral do trabalhador.

Cabe destacar nas palavras de Antonio Gramsci (2001) que: “[...] A divisão fundamental da escola em clássica e profissional era um esquema racional: a escola profissional destinava-se às classes instrumentais, enquanto a clássica destinava-se às classes dominantes e aos intelectuais". Tal ideia corrobora com o que acontece na história da educação brasileira no que diz respeito à educação profissional.

$\mathrm{Na}$ história da educação brasileira fica evidente uma contradição insolúvel entre a estrutura político-econômica, as relações sociais da sociedade e a necessidade de uma educação dual: uma escola clássica, de ampla base cientifica e cultural para as classes dirigentes e outra instrumental e de preparação profissional para os trabalhadores. Assim, trata-se de ensinar, treinar, adestrar, formar ou educar na função de produção adequada a um determinado projeto de desenvolvimento pensado pelas classes dirigentes (FRIGOTTO, 2005).

Para Antonio Gramsci,

A tendência atual é a de abolir qualquer tipo de escola "desinteressada" (não imediatamente interessada) e "formativa", ou de conservar apenas um seu reduzido exemplar, destinado a uma pequena elite de senhores e de mulheres que não devem 
pensar em preparar-se para um futuro profissional, bem como a de difundir cada vez mais as escolas profissionais especializadas, nas quais o destino do aluno e sua futura atividade são predeterminados. A crise terá uma solução que, racionalmente, deveria seguir esta linha: escola única inicial de cultura geral, humanista, formativa, que equilibre de modo justo o desenvolvimento da capacidade de trabalhar manualmente (tecnicamente, industrialmente) e o desenvolvimento das capacidades de trabalho intelectual. Deste tipo de escola única, através de repetidas experiências de orientação profissional, passar-se-á a uma das escolas especializadas ou ao trabalho produtivo (GRAMSCI, 2001).

Nesse sentido a educação profissional deve possibilitar a formação integral do trabalhador, equilibrando o desenvolvimento da capacidade de trabalhar tecnicamente com o desenvolvimento das capacidades de trabalho intelectual e não apenas formar apenas o trabalhador técnico.

A educação profissional e tecnológica revela uma possibilidade estratégica de contribuição para o desenvolvimento nacional resultado de transformações no decorrer das últimas décadas na Rede Federal de Educação, passando a ter visibilidade recentemente com a criação da Universidade Tecnológica Federal e a criação dos Institutos Federais de Educação, Ciência e Tecnologia (PORTAL MEC, 2008).

A educação profissional em faixas de fronteira pode possibilitar maior integração entre os países vizinhos, fazendo aproximações e cooperações que por vezes não são possíveis de serem concretizadas por instancias governamentais e por impedimentos de ordem burocrática.

Fazendo um aparte em relação à educação como fator de transformação social, é interessante trazer para a discussão as palavras de Vitor Paro no que diz respeito a tal tema, nas quais destaca: "a educação poderá contribuir para a transformação social, na medida em que for capaz de servir de instrumento em poder dos grupos sociais dominados em seu esforço de superação da atual sociedade de classes" (p. 103, 2000). Complementando ainda que, "a questão da educação enquanto fator de transformação social inscreve-se no contexto mais amplo do problema das relações entre educação e política” (Id. Ibid).

Neste sentido é preciso certo cuidado para não se perder nas ideias do senso comum quando o tema é educação, pois:

A legitimidade e o reconhecimento da educação estão impregnados no senso comum, tanto que frequentemente se ouvem pais argumentarem com os filhos que eles devem estudar, não pela compreensão de que a educação é um valor em si e um direito do ser humano, mas pelo fato de acreditarem que a escolarização possibilitará 
a seus filhos uma mobilidade social, demonstrando-se uma visão instrumental da educação (SOUZA, p. 27, 2013).

De acordo com Marx (2011, p. 25), “Os homens fazem a sua própria história; contudo, não a fazem de livre e espontânea vontade, pois não são eles quem escolhem as circunstâncias sob as quais ela é feita, mas estas lhes foram transmitidas assim como se encontram". Assim, a educação escolar, e no caso deste estudo a educação profissional integrada a uma educação integral do individuo pode possibilitar que mesmo com as interferências de todo um contexto que envolve aspectos econômicos, políticos e sociais, com que os homens possam fazer a sua própria história na medida em que empoderam-se mediante a emancipação humana e passam da condição de seres alienados de sua real condição para seres conscientes do poder de transformação da realidade ao seu entorno.

Diante da contextualização apresentada observa-se que educação e política são categorias vinculadas e necessárias para compreender a complexa relação do desenvolvimento de políticas de implantação de instituições de educação profissional em regiões de fronteira.

\section{Experiências de educação profissional nas fronteiras: IFSUL - Campus Santana do Livramento e do IFPR - Campus Foz do Iguaçu}

Em 2005, foi firmado um acordo entre os governos brasileiro e uruguaio para a implantação de Escolas e/ou Institutos binacionais Fronteiriços Profissionais e/ou Técnicos e para o credenciamento de cursos técnicos binacionais na zona de fronteira comum a ambos os países. O objetivo da criação dessas instituições foi promover a qualificação profissional, possibilitando a inclusão da população da área de fronteira, sendo a educação um fator de fortalecimento da integração (BRASIL, 2005).

A partir desse acordo, somado aos acordos de Cooperação Científica e Técnica de junho de 1975 e do Acordo de Residência, Estudo e Trabalho a Nacionais Transfronteiriços Brasileiros e Uruguaios de agosto de 2002, deu-se início em 2006 a primeira experiência de implantação de um Instituto Federal que ofertasse cursos binacionais (SILVA e LIMA, 2015).

Essa iniciativa partiu do então Centro Federal de Educação Tecnológica de Pelotas e agora Instituto Federal de Educação Sul-Rio-Grandense (IFSUL) e do Consejo de Educación Técnico Profesional da la Universidad del Tabajo del Uruguay (CETP-UTU). Em 2007, foi assinada a primeira ata entre as instituições, servindo de convênio para várias ações 
desenvolvidas até 2009: curso de qualificação profissional, intercâmbios, visitas técnicas e elaboração de projetos (Id. Ibid.).

Em 2009, com o incentivo da Secretaria de Educação Profissional e Tecnológica do Ministério da Educação (SETEC/MEC) e partindo de um diagnóstico de demandas laborais realizadas pelo Observatório do Mundo do Trabalho Regional Sul, iniciaram-se as ações para elaboração e oferta dos primeiros cursos binacionais no Campus Santana do Livramento (Id. Ibid.).

Em março de 2011, iniciaram as primeiras turmas na modalidade subsequente do Curso Técnico Binacional em Informática para Internet no Campus Santana do Livramento, e do Curso Técnico Binacional de Controle Ambiental, pela Escuela Técnica Superior de Rivera no Uruguai (Id. Ibid).

Essa é uma experiência pioneira no Brasil e que pode ser considerada exitosa, pois já completou ciclos de formação em dois cursos subsequentes e destes originaram-se mais seis cursos técnicos nas modalidades subsequente e integrada (Id. Ibid).

O percentual de vagas para cada curso tanto para os cursos do Campus Santana do Livramento quanto para a Escuela Técnica Superior de Rivera é de 50\% por cento para alunos brasileiros e $50 \%$ para alunos uruguaios, percentual este estipulado pelo acordo firmado em 2005 pelos dois países.

O convênio estabelecido entre o IFSUL e o Consejo de Educación Técnico Profesional de la Universidad del Trabajo del Uruguay (CETP-UTU) é uma cooperação internacional inédita, que ao que parece constitui uma forma mais efetiva integrada de ensino binacional na América do Sul. O ineditismo está no fato de que os diplomas dos cursos ofertados são reconhecidos por ambos os países, permitindo que o profissional atue em qualquer um deles sem a necessidade de revalidar seu diploma (DINIS e MELLO, 2015).

A oferta de cursos binacionais abre oportunidades de trabalho e estágio para os alunos em ambos os países, além de aproximar a população fronteiriça por meio da educação possibilitando o fortalecimento da integração entre os dois países.

O IFSUL - Campus Santana do Livramento encontra-se com desenvolvimento considerável em relação aos acordos e parcerias com o Uruguai, o que proporciona uma série de ações possíveis em ambos os lados da fronteira.

Na Tríplice Fronteira Brasil (Foz do Iguaçu) - Paraguai (Ciudad del Leste) Argentina (Puerto Iguaçu), o Instituto Federal do Paraná Campus Foz do Iguaçu, apesar de também estar em região de fronteira, apresenta outra realidade. 
Inicialmente no Campus Foz do Iguaçu, eram ofertadas vagas para alunos paraguaios, nos cursos subsequentes de Técnico em Aquicultura, Técnico em Cozinha e Técnico em Hidrologia, baseado no Programa Executivo Educacional entre o Governo da República Federativa do Brasil e o Governo da República do Paraguai, de 12 de abril de 2007, o qual aprofunda a cooperação bilateral no campo da educação entre os dois países. O percentual de vagas para alunos paraguaios era de $10 \%$ o que equivale a 4 vagas por curso.

Atualmente, após a suspensão dos cursos Técnico em Aquicultura e Técnico em Hidrologia, apenas o Curso Técnico em Cozinha oferta vagas para alunos transfronteiriços, sendo que a oferta foi ampliada para candidatos oriundos, além, da República do Paraguai para candidatos da República da Argentina.

O edital para seleção desses alunos está fundamentado no Decreto $n^{\circ} 2.689$, de 28 de julho de 1998, que promulga o Protocolo de Integração Educacional, Revalidação de Diplomas, Certificados, Títulos e de Reconhecimentos de Estudo de Nível Médio Técnico, assinado em Assunção, em 28 de julho de 1995. Aqui podemos observar apenas a fundamentação legal de parceria bilateral com o Paraguai. Com a Argentina não há um protocolo formal para oferta destas vagas.

Alguns trâmites relativos à documentação devem ser seguidos para que alunos transfronteiriços possam se matricular no curso. Os alunos paraguaios e argentinos devem seguir a regulamentação de fronteira entre estes países e a República Federativa do Brasil, para a providência de documentação exigida para sua circulação em território brasileiro.

Fato que desperta interesse e que não foi possível ainda verificar e que espera-se no decorrer da pesquisa de doutorado elucidar, é a diferença nos dois últimos editais de 2016 e 2017 para seleção de alunos estrangeiros, no Campus Foz do Iguaçu.

O Edital No 104/2016 foi destinado para seleção estudantes oriundos do Mercado Comum do Sul (MERCOSUL): Argentina, Paraguai, Uruguai e Venezuela, para ingresso no Curso Técnico em Cozinha, na forma de oferta subsequente, na modalidade presencial, para ingresso no ano letivo de 2017.

Por sua vez, o edital de seleção no 081/2017 do Processo Seletivo Simplificado para ingresso no Curso Técnico em Cozinha, Nível Médio, para de oferta Subsequente foi destinado para estudantes oriundos da República do Paraguai e República da Argentina.

Até o momento apenas alunos paraguaios ingressam nos cursos técnicos do IFPR Campus Foz do Iguaçu. Não há ainda uma política de cooperação e convênios firmados entre os países para validação no Paraguaio ou na Argentina dos diplomas expedidos pelo IFPR. Não há também uma política de acompanhamento destes alunos após conclusão dos cursos. 
Como é possível observar, por meio alguns apontamentos do histórico e das dinâmicas dessas duas instituições de educação profissional em cidades de fronteira, as experiências são bem diferenciadas e demanda um estudo mais aprofundado para compreender melhor a legislação, as relações internacionais e as políticas governamentais entre os países envolvidos.

Uma das diferenças entre as duas experiências que pode ser destacada é que, no caso do IFSUL - Campus Santana do Livramento há mais articulação na questão das relações internacionais e acordos de cooperação existentes entre o Brasil e o Uruguai, bem como o interesse das instituições governamentais locais, incluindo as instituições de ensino de ambos os países que tiveram interesse e força política para que os cursos binacionais fossem implantados. Tal experiência, acima descrita, no que diz respeito às relações internacionais e acordos de cooperação, ao que parece ainda não acontece no caso do IFPR - Campus Foz do Iguaçu em relação à Argentina e ao Paraguai, possivelmente devido às questões políticas que envolvem acordos de cooperação entre os países e talvez por falta de iniciativa por parte da comunidade de fronteira em buscar as instituições locais dos países vizinhos para estabelecer parcerias e acordos no sentido de implantação de cursos binacionais.

Outro ponto relevante para análise é de que o caráter conceitual das escolas de fronteira não se dá apenas pela localização, mas também pelo grau de interação da instituição com o país vizinho. Existem Campi que se localizam na região de fronteira e não tem qualquer interação com outro lado da fronteira. Existem outros que interagem com a população dos países vizinhos, mas não de forma institucionalizada, em ações isoladas. Um campus binacional, porém, tem a preocupação na integração em todas as suas ações, assim como em todas as suas decisões e em todas as suas ofertas (SILVA e LIMA, 2015).

\section{Considerações Finais}

Comparado as instituições destacadas neste estudo, localizadas em faixa de fronteira internacional, observa-se que o Campus Santana do Livramento (IFSUL) em relação às políticas transfronteiriças e de cooperação com o Uruguai apresenta uma condição consolidada, pois tem cursos binacionais em funcionamento desde 2011, com diplomas reconhecidos tanto pela instituição de ensino brasileira quanto pela uruguaia. Ao que parece há maior proximidade nas relações diplomáticas entre Uruguai e Brasil o que pode ser comprovados pelos acordos e convênios estabelecidos entre os dois países, como o Acordo Básico de Cooperação Científica e Técnica, estabelecido em 1997, o Acordo de Permissão de Residência, Estudo e Trabalho a Nacionais Fronteiriços Brasileiros e Uruguaios em 2002 e o 
Acordo de Criação de escolas e/ou Institutos Binacionais de Fronteiriços Profissionais e/ou Técnicos e para Credenciamento Técnico de Cursos Técnicos Binacionais Fronteiriços de 2005.

Somando-se a esses acordos, o interesse, o trabalho e a articulação das instituições e instâncias governamentais locais, ao que indica foi e está sendo fundamental para que a experiência do campus Santana do Livramento venha se estabelecendo como uma experiência exitosa na educação profissional binacional parece demonstrar que essa cooperação vem possibilitando a integração entre os dois países por meio da educação.

O Campus Foz do Iguaçu apresenta uma realidade bem diferente, pois está localizado em uma Tríplice Fronteira, já são outros países, outras instituições, enfim outras variantes que podem estar contribuindo para que o Campus ainda não tenha conseguido se desenvolver mais em relação a questão de talvez também de fato se tornar um Campus binacional. Pois, pode-se dizer que inicia sua caminhada em relação a oferta de educação profissional levando em consideração a fronteira, com uma oferta incipiente de vagas para alunos transfronteiriços, ainda sem nenhum acordo ou política implantada com os países com os quais ofertas as vagas para validação dos diplomas em seus países de origem.

O processo de criação, implantação e consolidação de Institutos Federais de Fronteira trazem desafios e dificuldades de tramitação legal, mas, também, podem ser uma oportunidade repleta de possibilidades de integração por meio da oferta de educação profissional.

A oferta de educação profissional possibilitada por instituições de diferentes países passa por um processo complexo, que envolvem a legislação, a elaboração de currículos, a escolha de processos de seleção dos alunos, a efetivação das matrículas e a legalidade dos diplomas emitidos para os estudantes dos países envolvidos.

Os Institutos Federais ofertam educação profissional e tecnológica; e, no que diz respeito aos institutos localizados em região fronteira, há que se considerar a elaboração de políticas educacionais que tenham um olhar sobre os alunos transfronteiriços, que compõem uma diversidade social e cultural que para além das questões burocráticas devem ser observadas.

Os Campi dos Institutos Federais localizados em zona de fronteira podem proporcionar um fluxo de estudantes transfronteiriços promovendo ações de integração entre as instituições de ensino dos países fronteiriços, sendo uma possibilidade que pode contribuir com a qualificação da população fronteiriça, consequentemente contribuindo desenvolvimento regional dessas localidades e melhoria da qualidade de vida nas fronteiras. 


\section{Referências}

ALBUQUERQUE, J. L. C. A Dinâmica das Fronteiras: deslocamento e circulação dos "brasiguaios" entre os limites nacionais. Horizontes Antropológicos, Porto Alegre, ano 15, n. 31, p. 137-166, jan./jun. 2009. Disponível em: http://www.scielo.br/pdf/ha/v15n31/a06v1531.pdf . Acesso em 27 dez. de 2018.

BALASSA, B. Teoria da Integração Econômica. Lisboa: Livraria Clássica Editora A. M. Teixeira \& (Filhos), 1982.

BRASIL. Acordo entre o Governo da República Federativa do Brasil e o Governo da República Oriental da Uruguai para a criação de Escolas e/ou institutos binacionais fronteiriços profissionais e/ou técnicos e para credenciamento de cursos técnicos binacionais fronteiriços, de 1 de abril de 2005. Brasília, DF. Disponível em: http://www.planalto.gov.br/ccivil_03/_ato2015-2018/2015/decreto/D8455.htm. Acesso em: 26 dez. de 2018.

BRASIL, Ministério da Integração Nacional. Proposta de Reestruturação do Programa de Desenvolvimento da Faixa de Fronteira, Brasília: Ministério da Integração Nacional, 2005. Disponível

em: https://docs.ufpr.br/ adilar/SEMIN\%C3\%81RIOS\%202018/Problem\%C3\%A1tica\%20Fronte iras/Programa\%20Nacional\%20Faixa\%20Fronteira.pdf. Acesso em: 27 dez. de 2018.

CURCIO, D. da R. Cooperação e Integração na Fronteira Brasil-Uruguai Desafios e Perspectivas na Implantação de Cursos Binacionais de Educação Técnica. Anais do I Congresso Brasileiro de Geografia Política, Geopolítica e Gestão do Território, 2014.

DINIS, M. A. P.; MELLO, L. M. de. Cursos binacionais: relatos de uma experiência. Santana do Livramento: Ed. Cia do eBook, 2015.

FLICK, U. Introdução a Pesquisa Qualitativa. Tradução: Joice Elias Costa. $3^{a}$ ed. Porto Alegre: Artmed, 2009.

ENGELS, F. A Origem da Família, da Propriedade Privada e do Estado. Tradução de Leandro Konder. $9^{a}$ ed. Rio de Janeiro, Civilização Brasileira, 1984.

FRIGOTTO, G.; CIAVATTA, M.; RAMOS, M. Educação Profissional e Desenvolvimento. Coletânea organizada pelo Centro Internacional de Educação Técnica e Profissional, com o patrocínio da UNESCO. Berlim, 2005. Disponível em: http://redeescoladegoverno.fdrh.rs.gov.br/upload/1392219264_Educa\%C3\%A7\%C3\%A3o\%2 0Profissional\%20e\%20Desenvolvimento.pdf. Acesso em: 07 set. 2016.

GRAMSCI, A. Cadernos do Cárcere. Volume 2. $2^{\circ}$ ed. Rio de Janeiro: Civilização Brasileira. 2001.

LEGNANI, A. M.; CURY, M. J. F. A Política de Implantação dos Institutos Federais de Fronteira: um estudo comparado IFSUL-campus Santana do Livramento e IFPR- campus Foz do Iguaçu. In: Olhares interdisciplinares sobre território e as territorialidades em fronteiras. Curitiba: CRV, 2018. 
LUCHETTI, L, A. O papel desempenhado pelo estado no estabelecimento de políticas sociais em áreas de fronteira. In: Contribuciones a las Ciencias Sociales, 2014. Disponível em: < www.eumed.net/rev/cccss/27/políticas-sociales-fronteras.html >. Acesso em: 04 set. 2016.

MARX, K.; ENGELS, F. Manifesto Comunista. $4^{\text {a }}$ ed. Tradução Alvaro Pina. São Paulo: Boitempo, 2005.2 Disponível em: https://edisciplinas.usp.br/pluginfile.php/2545967/mod_resource/content/1/MARX\%3B\%20E NGELS.\%20Manifesto\%20Comunista.pdf . Acesso em: 26 de dez. de 2018.

MARX, K. 1818-1883. O capital: crítica da economia política. 35a ed. Rio de Janeiro: Civilização Brasileira, 2017.

\section{Boitempo, 2011. Disponível em: https://edisciplinas.usp.br/pluginfile.php/2804654/mod_resource/content/0/Marx\%20- \%200\%2018\%20Brum\%C3\%A1rio\%20de\%20Lu\%C3\%ADs\%20Bonaparte\%20\%28Boitem po\%29.pdf. Acesso em: 26 de dez. de 2018.}

NOGUEIRA, R. J. B. Fronteira: Espaço de Referência Identitária? Revista Ateliê Geográfico da Universidade Federal de Goiânia - UFG/IESA. V.1, n.2, Dez/2007, Goiânia-GO, 2007. Disponível em: http://www.revistas.ufg.br/index.php/atelie/article/view/3013/3051. Acesso em: 04 set. 2016.

NÓVOA, A. Modelos de análise de educação comparada: o campo e o mapa. In: Educação Comparada: rotas além-mar. Donaldo Bello de Souza e Silvia Alicia Martinez (organizadores). São Paulo: Xamã, 2009.

PARO, V. H. Administração Escolar: Introdução Crítica. 9 ed. São Paulo: Cortez, 2000.

PESAVENTO, S. J. Além das fronteiras. In: Fronteiras Culturais: Brasil - Uruguai Argentina. MARTINS, Maria Helena. (org.). São Paulo: Ateliê Editorial, 2002.

PORTAL MEC. Histórico da Educação Profissional. 2008. Disponível em: http://portal.mec.gov.br/setec/arquivos/centenario/historico_educacao_profissional.pdf.

Acesso em: 5 set. 2016.

RAFFESTIN, C. Por uma Geografia do Poder. Tradução Maria Cecília França. São Paulo: Editora Ática. 1993.

SILVA, A.; LIMA, P. H. A. O contexto dos Cursos Binacionais na Fronteira Sant'Ana do Livramento-BR/Rivera-UY. In: Cursos binacionais: relatos de uma experiência inovadora. /Miguel Angelo Pereira Dinis, Luciano Moura de Mello. Santana do Livramento: Ed. Cia do eBook, 2015.

SOUZA, S. A. de. Educação, trabalho voluntário e responsabilidade social. São Paulo: Xamã, 2013. 
TCU. Tribunal de Contas da União. Relatório: Auditoria Operacional. Avaliação de Governança de Políticas Públicas. Fortalecimento da Faixa de Fronteira. 2014. Disponível em:

http://portal.tcu.gov.br/lumis/portal/file/fileDownload.jsp?fileId=8A8182A24F99F813014FB 44F0D0500F4\&inline=1. Acesso em: 04 set. 2016. 